\title{
Severe systemic vasculitis in a neonate
}

\author{
Giacomo D. Simonetti • Regula Markwalder • \\ Martin Tönz • Juerg Pfenninger • Mario G. Bianchetti
}

Received: 3 May 2006 / Accepted: 26 June 2006 / Published online: 7 September 2006

(C) Springer-Verlag 2006

Keywords Systemic vasculitis · Neonatology . Glomerulonephritis

\section{Introduction}

Vasculitides are unusual in neonates with the exception of transient vasculitides in infants of mothers affected by vasculitides mediated by proteins, which are transported across the placenta to the fetus $[1,4,5]$. We report here a systemic neonatal vasculitis in the son of a healthy woman.

\section{Case report}

A full-term male newborn, the child of a healthy Swiss woman with normal urinalysis and negative tests for hepatitis $\mathrm{B}$, hepatitis $\mathrm{C}$ and human immunodeficiency virus,

Giacomo D.Simonetti: supported by Fondazione Ettore e Valeria Rossi.

G. D. Simonetti $\cdot$ J. Pfenninger $\cdot$ M. G. Bianchetti Department of Pediatrics, University of Berne,

Berne, Switzerland

R. Markwalder

Department of Human Pathology, University of Berne,

Berne, Switzerland

\section{Tönz}

Department of Pediatric Surgery, University of Berne,

Berne, Switzerland

M. G. Bianchetti $(\bowtie)$

Ospedale San Giovanni,

6500 Bellinzona, Switzerland

e-mail: mario.bianchetti@pediatrician.ch was referred for surgical repair of esophageal atresia and distal tracheoesophageal fistula at the age of 2 days. Three days later, the diagnosis of anastomotic leak and infected right-sided pneumothorax was made, which required parenteral antimicrobial treatment with clindamycin and amoxicillin based on positive cultures for both viridans streptococci and coagulase-negative staphylococci. In spite of that the child developed a severe pleural empyema, which was treated with thoracotomy and decortication. The antimicrobial medication was continued up to the age of 21 days. Two days later, the condition of the child deteriorated, as indicated by the appearance of tachypnea, progressive cyanosis, and reduced diuresis. Chest x-ray findings disclosed intraalveolar fluid accumulation. Laboratory values were as follows: hemoglobin, $91 \mathrm{~g} / 1$ (reference range, $100-150 \mathrm{~g} / \mathrm{l})$; white blood cell count, $19.8 \times 10^{9} / 1$ (reference range, $5.0-12.5 \times 10^{9} / 1$ ); platelets, $39 \times 10^{9} / 1$ (reference range, $\left.150-300 \times 10^{9} / 1\right)$; C-reactive protein, $118 \mathrm{mg} / \mathrm{l}$ (reference range, $\leq 5 \mathrm{mg} / \mathrm{l}$ ); creatinine, $92 \mu \mathrm{mol} / \mathrm{l}$ (reference range, $\leq 47 \mu \mathrm{mol} / \mathrm{l})$. A blood film disclosed a moderate eosinophilia of $3.9 \times 10^{9} / 1$ (reference range: $\leq 0.8 \times 10^{9} / 1$ ). Urinalysis disclosed severe proteinuria, hematuria and red blood cell casts. Two days later, a generalized maculopapular rash was noted.

Antineutrophil cytoplasmic and antinuclear autoantibodies, and antibodies against the Ro and La particle were not present in either the patient or his mother. The tentative diagnosis of systemic vasculitis was confirmed by a skin biopsy demonstrating a characteristic leucocytoclastic vasculitis with marked eosinophilia (Fig. 1). Immunofluorescence studies with antisera against immunoglobulins were not performed.

Medical treatment with methylprednisolone $3 \mathrm{mg} / \mathrm{kg}$ body weight daily was followed within 24 hour by polyuria 


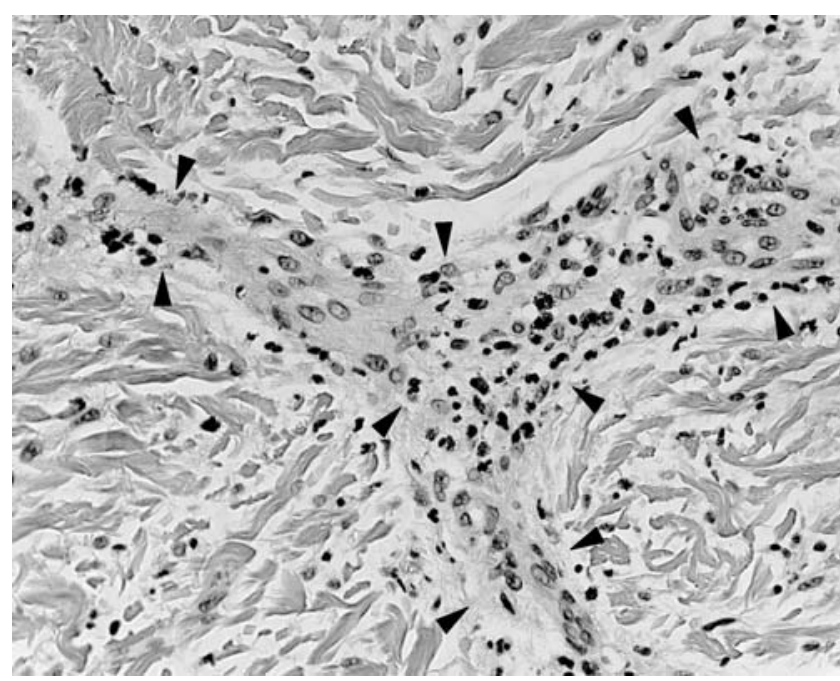

Fig. 1 Skin biopsy specimen showing a blood vessel (arrows) with parietal and perivascular eosinophilic and neutrophilic infiltrates. Nuclei of inflammatory cells are in part fragmented and pycnotic

and normalization of plasma creatinine (36 $\mu \mathrm{mol} / \mathrm{l})$. Urinalysis failed to disclose pathological proteinuria and hematuria 5 days later and the treatment with methylprednisolone was pursued for no more than 7 days. The subsequent acute course was uneventful. On follow-up, 5 and 12 months later, the child was well and its urinalysis normal.

\section{Discussion}

The most frequent cases of systemic neonatal vasculitis occur in infants of mothers affected by Behçet disease, systemic lupus erythematosus, Sjögren syndrome, undifferentiated connective tissue disease or microscopic polyarteritis $[1,4]$. Kawasaki disease is a further systemic vasculitis that exceptionally occurs in neonates [5]. Also known as Finkelstein disease, Seidlmayer disease or infantile Schönlein-Henoch purpura, acute hemorrhagic edema of infancy is a rather frequent self-limiting cutaneous vasculitis without any systemic involvement that presents sometimes at birth [3]. In our patient history, symptoms and signs were not compatible with the mentioned conditions.

The severe eosinophilic vasculitis noted in our newborn did not recur after short-term steroid treatment. This fact strongly argues for a vasculitis secondary either to drugs or acute infections [2, 6]. Both streptococci and staphylococci, the causative agents of the severe thoracic infection of our patient, have been known or suspected to cause vasculitides. On the other side, many therapeutic agents including amoxycillin and clindamycin can induce a variety of vasculitic manifestations. We feel that the role played by streptococci, staphylococci or amoxycillin in the systemic vasculitis of our patient is impossible to answer.

In conclusion, pediatricians and neonatologists should be aware that systemic vasculitides can occur in a neonate even if his mother is not affected.

\section{References}

1. Boh EE (2004) Neonatal lupus erythematosus. Clin Dermatol 22:125-128

2. Cuellar ML (2002) Drug-induced vasculitis. Curr Rheumatol Rep 4:55-59

3. Cunningham BB, Caro WA, Eramo LR (1996) Neonatal acute hemorrhagic edema of childhood: case report and review of the English-language literature. Pediatr Dermatol 13:39-44

4. Fain O, Mathieu E, Lachassinne E, Buisson P, Bodemer C, Gaudelus J, Thomas M (1995) Neonatal Behcet's disease. Am J Med 98:310-311

5. Krapf R, Zimmermann A, Stocker F (1981) Lethal vasculitis of coronary arteries in a neonate and two infants: possible neonatal variant of the MLNS/IPN complex? Helv Paediatr Acta 36:589598

6. Mohan N, Kerr G (2003) Infectious etiology of vasculitis: diagnosis and management. Curr Rheumatol Rep 5:136-141 